
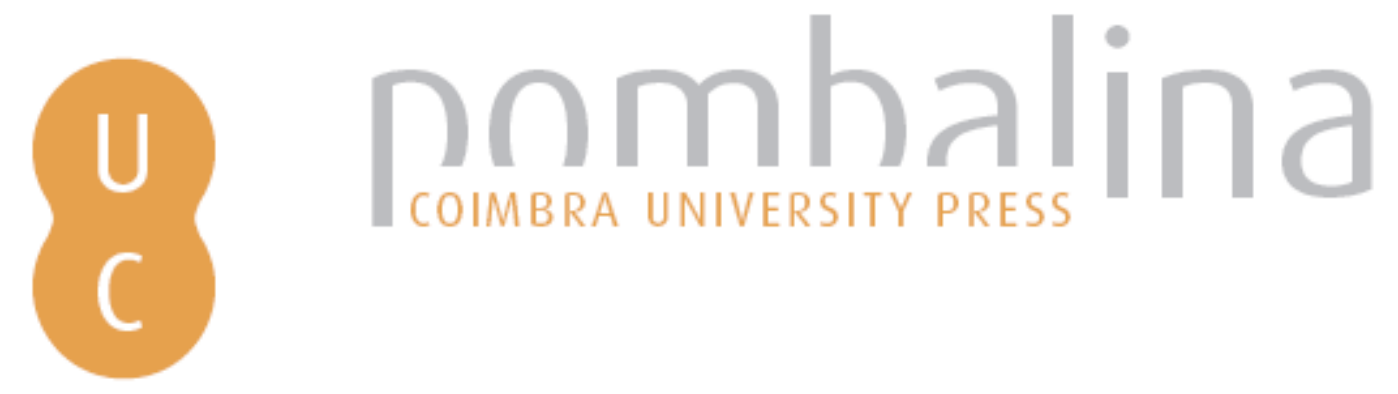

\title{
Alterações ambientais recentes e riscos associados no médio curso do rio zêzere: o couto mineiro da Panasqueira
}

\author{
Autor(es): $\quad$ Gonçalves, Anselmo Casimiro Ramos \\ Publicado por: Imprensa da Universidade de Coimbra \\ URL \\ persistente: URI:http://hdl.handle.net/10316.2/31183 \\ DOI: $\quad$ DOI:http://dx.doi.org/10.14195/978-989-26-0244-8_85 \\ Accessed : $\quad$ 26-Apr-2023 06:01:13
}

A navegação consulta e descarregamento dos títulos inseridos nas Bibliotecas Digitais UC Digitalis, UC Pombalina e UC Impactum, pressupõem a aceitação plena e sem reservas dos Termos e Condições de Uso destas Bibliotecas Digitais, disponíveis em https://digitalis.uc.pt/pt-pt/termos.

Conforme exposto nos referidos Termos e Condições de Uso, o descarregamento de títulos de acesso restrito requer uma licença válida de autorização devendo o utilizador aceder ao(s) documento(s) a partir de um endereço de IP da instituição detentora da supramencionada licença.

Ao utilizador é apenas permitido o descarregamento para uso pessoal, pelo que o emprego do(s) título(s) descarregado(s) para outro fim, designadamente comercial, carece de autorização do respetivo autor ou editor da obra.

Na medida em que todas as obras da UC Digitalis se encontram protegidas pelo Código do Direito de Autor e Direitos Conexos e demais legislação aplicável, toda a cópia, parcial ou total, deste documento, nos casos em que é legalmente admitida, deverá conter ou fazer-se acompanhar por este aviso.

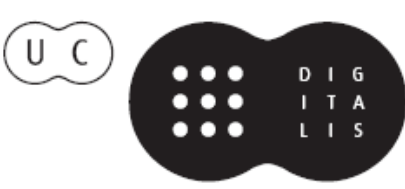




\section{TRUNFOS DE UMA}

\section{EOGRAFIA ACIVA}

\section{DESENVOLVIMENTO LOCAL,}

AMBIENTE,

ORDENAMENTO

E TECNOLOGIA

Norberto Santos

Lúcio Cunha

COORDENAÇÃO 
Anselmo Casimiro Ramos Gonçalves

\section{ALTERAÇÓES AMBIENTAIS RECENTES E RISCOS ASSOCIADOS NO MÉDIO CURSO DO RIO ZÊZERE - O COUTO MINEIRO DA PANASQUEIRA}

\section{ENQUADRAMENTO TEMÁTICO}

Nos últimos 30 anos, o interesse pelos problemas ligados ao ambiente aumentou de forma impressionante, inscrevendo-se, hoje na lista de preocupaçóes da Administraçáo Pública e das Organizaçóes não Governamentais nacionais e internacionais.

É a partir de 2002 com a Cimeira de Joanesburgo, que nove das mais importantes companhias mineiras a nível mundial decidiram iniciar um projecto designado por Minning Minerals and Sustenaible Development (MMSD), cujos objectivos fundamentais se resumiam a: 1) Avaliação do sector mineral em termos globais; 2) Identificação do modo como os serviços prestados pelo sistema mineral podem ser desempenhados de forma sustentável no futuro.

A verdade é que a maior parte das actividades desenvolvidas pelo Ser Humano são em maior ou menor percentagem, agressivas para o ambiente. É nesta perspectiva que a indústria extractiva contribuiu e contribui para as modificaçóes ambientais. Embora gerando riqueza a verdade é que, envolve uma degradação do ambiente, acarretando dessa forma um conjunto importante de mudanças ambientais e socioeconómicas.

Em verdade, podemos afirmar que a actividade mineira deve a sua localizaçáo a factores meramente naturais, é que os efeitos por ela induzidos no ambiente estáo interligados com o tipo de material a explorar, com a área onde está inserida e com o método e o tipo de exploração.

\section{ENQUADRAMENTO GEOGRÁFICO}

O Couto Mineiro da Panasqueira localiza-se no distrito de Castelo Branco, nos limites dos concelhos da Covilhã, Fundão e Pampilhosa da Serra (figura 1), com uma área total de $21 \mathrm{Km}^{2}$. Fica situado em pleno Maciço Hespérico, a sul da Serra da Estrela, entre os maciços da Serra do Açor e da Gardunha, a poente da depressão tectónica designada de "Cova da Beira".

A sul destas minas passa, no sentido Nascente - Poente, o rio Zêzere, principal receptor de todas as linhas de água da região e de onde se retirava toda a água fundamental ao tratamento mecânico do minério extraído. 
O centro mineiro criado pela Beralt Tin \& Wolfram, situa-se na Barroca Grande, onde se concentra toda a actividade mineira.

Figura 1 - Localização geral da área analisada. Adaptado de S. Valente (2008)

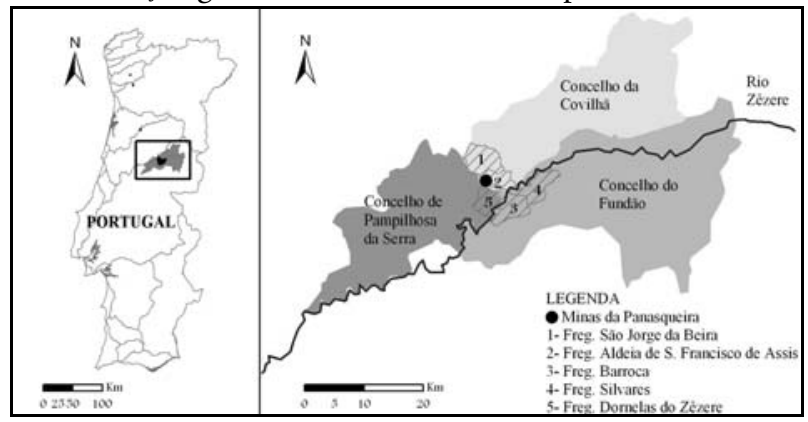

\section{ALTERAÇÓES AMBIENTAIS RECENTES NO COUTO MINEIRO DA PANASQUEIRA}

As Minas da Panasqueira não são, no panorama nacional, uma excepção, em especial o Cabeço Pião (concelho do Fundão), local onde foi tratado o minério durante dezenas de anos e onde estão as maiores escombreiras resultado desse tratamento, paredes meias com o rio Zêzere.

As enormes escombreiras de estéreis aqui mencionadas são compostas essencialmente por partículas de quartzo, xistos e grauvaques que de alguma forma estáo associados ao jazigo e apresentam diferente granulometria.

Frequentemente, são as escombreiras de minas abandonadas o principal foco de poluição, por incluírem sulfuretos capazes de reagirem até formarem águas ácidas, aumentando o poder de dissolução de elementos químicos tóxicos, lixiviando-os e transportando-os, por vezes até distâncias consideráveis da origem, e resultando na contaminação de águas superficiais ou subterrâneas.

A ausência de responsabilidade que progressivamente se instalou com o encerramento de minas, cria nos dias de hoje sérias dificuldades à aplicação do princípio do poluidor pagador, pelo que perante tal estado de coisas compete hoje ao Estado a resoluçáo desses problemas. Ao contrário, tem havido por parte da BTWP nos últimos anos alguma preocupação com a monitorização das águas vindas da mina (fonte do Masso e da Salgueira). Crespo (2006, p. 1) manifesta mesmo preocupação com a dificuldade actual da ETAR existente já náo ter capacidade para tratar de forma integral os efluentes líquidos vindos quer da mina, quer ainda da barragem de lamas. Geralmente as escombreiras evoluem em área e altura na proporçáo directa do aprofundamento da exploração, caso das escombreiras da Barroca Grande e do Cabeço do Piáo.

Independentemente dos problemas geotécnicos que lhe estão associados (instabilidade de taludes, erosão laminar, ravinamentos, erosão eólica, assentamentos, modificaçóes na drenagem, etc...), e que, por vezes, podem ser os mais importantes, são os impactes de natureza paisagística que chamam mais a atenção por parte das populações e, principalmente, dos visitantes dessas regióes, em particular em meios rurais de acentuada beleza cénica. 


\section{IMPACTE VISUAL}

A paisagem é apreendida como qualquer coisa de figurativo e pode considerar-se como o resultado de uma interacção entre a natureza (suporte físico), condicionada pelos factores morfogeológicos e climáticos e as actividades humanas (condicionadas pelos factores sociais e económicos), deste modo, a paisagem não é mais do que um complexo dinâmico do qual o observador faz parte integrante.

Em regiōes mineiras a recuperar, não sendo possível a cópia das anteriores condiçóes naturais, segundo A. Gonçalves (2007), a fase de desactivação pode levar a várias soluçóes de recuperação paisagística, entre elas a transformação, através de diversos tratamentos do solo, restituindo-lhe, um aspecto visual aceitável, utilizando de preferência a vegetação autóctone.

\section{IMPACTE SOBRE OS SOLOS E AS ÁGUAS}

Um dos riscos ambientais mais preocupantes, associados a escombreiras que resultaram ou resultam duma intensa actividade mineira, consiste na contaminação (por metais pesados e substâncias utilizadas no tratamento do minério, etc) dos sistemas ambientais que envolvem a respectiva escombreira.

A contaminação por metais é particularmente importante nos casos em que ocorrem drenagens ácidas a partir de sulfuretos depositados na escombreira. A drenagem destas águas ácidas para o meio circundante, respectivamente para as linhas de água, provoca a dispersão dos metais e a contaminação e acidificação das águas superficiais, subterrâneas e dos solos.

Além das drenagens ácidas, a disseminação de contaminantes a partir dos materiais depositados nas escombreiras também pode ser processado devido aos fenómenos erosivos (hídrica e eólica), e aos deslizamentos de massa, que contribuem para carrear as partículas das escombreiras para as linhas de água e terrenos circundantes.

F. Ojea (1995) aponta mesmo outros efeitos devido à elevada queda de precipitaçáo, gera-se acção erosiva que é potenciada pela presença de declives elevados, provocando o surgimento de ravinas. Nessa perspectiva F. Rebelo (1994, p. 10) aponta para situaçóes complicadas nas imediaçóes das minas, chamando à atenção que em "climas como os nossos, podem surgir problemas graves de movimentaçôes em massa ou fornecem muito material sem coesão para movimentaçôes individuais em ravinas que entretanto se formem uma vez que, em regra, não é fácil a sua fixação natural pelas espécies vegetais mais frequentes".

A erosão hídrica é sem dúvida alguma a mais significativa e a que mais efeitos prejudiciais pode causar, manifestando-se, no entanto, de diversas maneiras. A erosão por salpicos (efeito splash), provocada pelo impacto da gota de água da chuva, acciona o mecanismo de desagregação das partículas levantando as mais pequenas. Este efeito é tão mais intenso em escombreiras que estão desprovidas de qualquer tipo de vegetação. Por outro lado, quando a intensidade da precipitação ultrapassa a capacidade de absorção de água por parte do material que compóe a escombreira, inicia-se aí o escoamento superficial que, e em função da altura do escoamento e a inclinação do talude arrasta os materiais levantados pelo efeito splash. Quando a erosão é mais intensa e existe um superavit de água em movimento esta provoca feridas profundas na escombreira, que podemos designar por ravinas. Nestas situaçôes as paredes laterais das ravinas por falta de sustentabilidade e coesão podem provocar desprendimentos dos materiais devido ao excesso de humidade. 
No que se refere aos factores externos podemos referenciar a precipitação e a cobertura vegetal da escombreira; no que aos factores internos diz respeito há a considerar as propriedades do material da escombreira (textura, permeabilidade e conteúdo em matéria orgânica), a inclinaçáo, o comprimento e o perfil dos taludes. Perante o agravamento dos factores mencionados, aumenta a quantidade de material que é removido da escombreira e depositado nos cursos de água conduzindo a médio prazo ao seu assoreamento. Devemos reter, no entanto, que o efeito que mais rapidamente se faz sentir perante esta situação tem a ver com o aumento das partículas em suspensão na água modificando dessa forma a sua qualidade. Com o aumento dos sólidos em suspensão aumenta a turvação da água interferindo no uso da mesma (consumo e rega), fragilizando o valor estético e interferindo dessa forma no equilíbrio ecológico dos diversos ecossistemas em causa.

Dos metais pesados destacam-se o $\mathrm{Cu}, \mathrm{Zn}, \mathrm{Fe}, \mathrm{Mn}$, As, e todos estes assumem um papel determinante nos processos metabólicos dos seres vivos e provavelmente serão os responsáveis por algumas catástrofes ecológicas, dado que podem registar processos significativos de bioacumulação e ter consequências nefastas na cadeia alimentar, até ao próprio Ser Humano. A sua presença em águas subterrâneas resultando de processos de lixiviação de zonas da crusta fortemente mineralizadas ou simplesmente enriquecidas é comum, mas a existência de aumentos significativos nas concentraçóes desses metais no meio hídrico de zonas mineiras pode estar directamente relacionada com fenómenos de lixiviação de escombreiras e outros materiais extraídos das minas.

O calibre muito fino dos materiais depositados na escombreira, devido em grande parte, à fragmentação operada na oficina de separaçáo e de tratamento de minérios, acelera, em geral, os processos de dissoluçáo e lixiviação. Assim, podemos inferir que uma das fontes de maior significado poluente está ao nível dos metais já mencionados, os quais integram em percentagens mais ou menos relevantes as escombreiras deste couto mineiro.

Há a realçar que os processos de contaminação dos solos consistem na sua essência na descarga acidental ou não, de óleos e combustíveis; no abandono ou enterramento premeditado de resíduos industriais (baterias, sucatas, etc.); na acidificação do solo, provocada pela circulação de águas ácidas na contaminação por metais pesados, difundidos a partir das escombreiras e barragem de lamas.

\section{IMPACTE SOBRE A FAUNA E A FLORA}

A actividade mineira produziu e produz no ecossistema local impactes de diversa natureza, através da alteração de algumas das suas características naturais. Os efeitos nocivos que este tipo de indústria produz vão desde a perda de vegetação, devido às cargas contaminantes lançadas para o ar livre e para a água, assim como amplia a actividade erosiva em virtude do desaparecimento da vegetação herbácea e arbustiva. Aliás, é um erro pensar que a perda da vegetaçáo rasteira é menos importante do que a perda de árvores, pois é a vegetação rasteira que diminui a acção erosiva, assim como fornece alimento e abrigo a variadíssimas espécies animais.

As poeiras, a decapagem do solo e a contaminação química deste podem impedir o crescimento da vegetação e inibir os fenómenos respiratórios e fotossintéticos das plantas, conduzindo a uma diminuição da capacidade de regeneração e de reprodução, a uma alteração das cadeias alimentares e a uma destruição de espécies raras, vulgares e / ou protegidas. A 
diminuição do coberto vegetal vai afectar certas comunidades faunísticas pela destruição dos locais de nidificação, alimentação e refúgio. $\mathrm{O}$ ruído resultante do tráfego de camióes, instalaçóes de tratamento, os desmontes, etc, modificam o comportamento das espécies, alterando-lhes os hábitos alimentares e reprodutores.

Também os impactes das exploraçóes mineiras sobre os solos pode afectar negativamente a flora e a fauna, os metais pesados ao serem absorvidos pelas plantas podem provocar a sua morte ou impedir o seu crescimento, assim, os metais ao entrarem na cadeia trófica acabam invariavelmente por atingir a fauna.

\section{Riscos NATURAIS E AMBIENTAIS ASSOCIADOS À ACTIVIDADE MineIRA}

Reflectir sobre os riscos naturais e ambientais induzidos pela actividade mineira não pode ser de modo algum entendido como alarmista, mas sim como uma atitude de consciencialização das populaçóes, das entidades municipais e estatais responsáveis pela gestão do risco, assim como das próprias empresas mineiras.

As modificaçôes na morfologia, a perda de solo, a alteração da qualidade da água, a inevitável perda de vegetação e as modificaçóes na rede de drenagem, causadas pela exploração e aliadas às escombreiras ou mesmo às galerias subterrâneas, podem induzir, nas zonas envolventes, um aumento do risco de desprendimentos, deslizamentos e escorregamentos dos taludes e mesmo abatimento de terrenos (subsidências), aumento da carga sólida dos cursos de água com assoreamentos e consequentes inundaçóes. Segundo F. Ladeira, citado por P. Fava (1999, p. 98) os movimentos de massa embora dependentes de factores externos como a precipitaçáo, estáo no entanto condicionados pelas características geológicas e geotécnicas inerentes às escombreiras, o que torna este tipo de movimentos um assunto privilegiado na questão da estabilidade destas. Independentemente ao facto de existirem inúmeras classificaçóes para este tipo de movimentos, apresentamos de seguida aqueles que nos parecem os que apresentam um maior significado para a estabilidade / instabilidade de taludes de escombreiras.

Figura 2 - Principais tipos de roturas em escombreiras de acordo com a geometria: a) rotacional; b) mista; c) translacional. Figura retirada de ITGE (1989, p. 33).

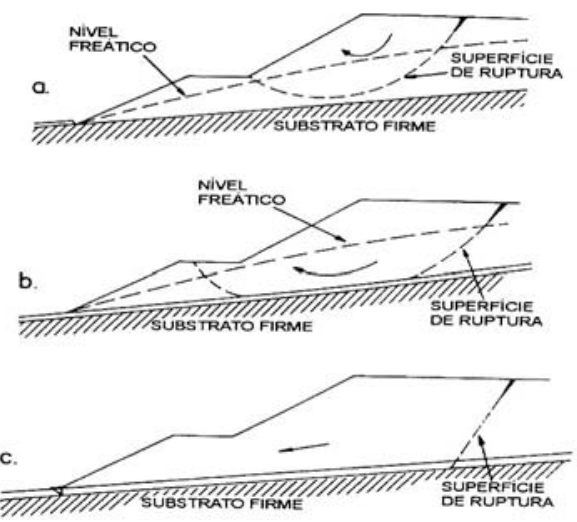


As formas de instabilidade (figura 2) em escombreiras segundo o ITGE (1989, p. 33) podem classificar-se tendo em conta a posição da superfície de rotura em: 1) Superficiais, quando náo afectam a base da escombreira; 2) Profundas, sempre que atingem a base da escombreira.

Nessa perspectiva podemos identificar os tipos de rotura de acordo com a geometria das mesmas. Assim temos: Deslizamentos rotacionais (a) - próprios de materiais com granulometrias finas e com propriedades geotécnicas homogéneas; por regra adopta-se um arco de circunferência para a superfície de escorregamento; -Deslizamentos mistos (b) - Trata-se de movimentos bastante complexos geralmente associados a escorregamentos rotacionais que incluem componentes translacionais e/ou do tipo fluxo na sua base; 3) Deslizamentos translacionais (c) (cunha) - próprios dos materiais com fortes anisotropias, estas roturas ocorrem através de um plano; é um tipo de movimento que poderá ocorrer quando a base de apoio da escombreira não é suficientemente resistente para suportar o peso dos estéreis.

Após o encerramento da mina deveriam ter sido efectuados estudos de avaliaçáo de riscos o que, à época (1965 na Panasqueira e em 1995 no Cabeço do Pião), não nos parece ter sido a principal preocupaçáo da empresa. Esses estudos deveriam ter sido realizados de forma a detectar os pontos mais vulneráveis que poderiam surgir após o encerramento da mina, tais como: Instabilidade de escombreiras, que se traduz geralmente em movimentos de vários tipos (creep, deslizamentos, desenvolvimento de ravinas, etc.), condicionados por diversos factores intrínsecos (tipo de material e granulometria, variaçóes de temperatura e humidade, queda intensa de precipitaçáo seja em curtos períodos de tempo ou em períodos mais dilatados, efeito de vibraçóes, mecanismos erosivos, etc), e que pode ter consequências gravosas para pessoas e equipamentos, obstrução de vias de comunicação, assoreamento de rios, e por vezes em funçáo da quantidade do material deslizado poderá este bloquear provisoriamente a totalidade do curso de água, funcionando como barragem, criando aqui a acumulação de água a montante.

São normalmente casos como este que assumem um aspecto mais catastrófico pois o efeito momentâneo de barragem ao ser removido, favorece o aparecimento de uma nova frente destruidora de água e lama, eventualmente contaminada por metais pesados que invariavelmente vão inviabilizar a prática da agricultura por um largo período de tempo nos campos atingidos pela enxurrada. G. Guidicini e C. Nieble (1983), referem ainda outro tipo de situaçóes entre elas: 1) Queda de material das escombreiras próximas de habitaçóes, de estradas, de caminhos; 2) Efeitos nos solos através da perca acelerada da fertilidade dos solos aráveis por contaminação.

Os riscos sobre os recursos hídricos consistem fundamentalmente na alteração da circulação superficial e subterrânea e modificaçooes das características físico-químicas das águas que segundo o ITGE, 1989 poderão surgir através de:

- Escorrência das águas nas escombreiras que poderão invadir propriedade privada e pública e que poderão criar problemas de saúde pública, etc.

- Subsidências na superfície como resultado natural da extracção subterrânea. A extracção de material em profundidade induz uma maior compactação das rochas face à pressão litostática sobrejacente, conduzindo à ocorrência de planos de deslocamento que afloram à superfície do terreno, resultando em movimentos verticais e consequentes deformaçóes na superfície. Segundo ITGE (1989), os movimentos de subsidência são controlados por dois grupos de factores: geológicos (que têm a ver com a as características litológicas, hidrogeológicas, geomecânicas da área explorada.), e mineiros que tem a ver com os métodos de 
exploraçáo e profundidade alcançada pelos trabalhos. O colapso de chaminés, galerias e poços, pode provocar depressóes topográficas e cavidades no terreno, causando dessa forma danos às estruturas superficiais tais como edifícios, rede de distribuição de água, caminhos, estradas, etc.

Depois de ocorrer o abandono da mina os problemas de instabilidade tendem a agravar-se devido ao elevado grau de degradação das estruturas de suporte estabelecidas durante a exploração, constituindo um factor de risco para a segurança de pessoas, bens e animais das zonas limítrofes.

\section{CONCLUSÃo}

Perante o cenário traçado, podemos afirmar que as alteraçóes ambientais verificadas sáo consequência da actividade mineira centenária, que conduziu a uma situaçáo geradora de riscos ambientais, cujo efeito agressivo não podemos menosprezar.

As deficientes condiçóes de drenagem, associadas a uma acentuada degradação das estruturas das escombreiras, constituem actualmente causa da instabilidade física observada na sua superfície em especial ravinamentos e cicatrizes que evidenciam deslizamentos que entram em contacto com o rio Zêzere directamente.

Assim, devido ao agravamento da instabilidade da escombreira a que podemos associar a acção erosiva da água e do vento, têm sido carreados para a principal linha de água o Zêzere e para os solos da zona envolvente quantidades consideráveis de estéreis de granulometria fina, que de alguma forma têm contribuído para a não utilização dos terrenos para a prática da agricultura, como já atrás referenciámos.

Também consideramos importante reperfilar e estabilizar os taludes artificiais de forma a reduzir os declives das escombreiras.

Os trabalhos a realizar nesta escombreira, passam pela movimentação de terrenos, rochas e solos, destinados à construção dos taludes artificiais de forma a reduzir ou mesmo eliminar os constantes deslizamentos de material da escombreira para o Zêzere. Este trabalho deverá ser acompanhado pela implementaçáo de um eficaz sistema de drenagem, que evite ou reduza exponencialmente os lexiviantes, que de outra forma vão directamente para o rio, este trabalho deverá ter em conta um correcto repovoamento arbustivo e arbóreo que venha futuramente a esbater o contraste cromático existente.

Após os trabalhos efectuados a monitorização das águas do rio Zêzere deverá ser constante de forma a acompanhar a evoluçáo da sua qualidade.

\section{REFERÊNCIAS BIBLIOGRÁFICAS}

Crespo, E. (2006) - "Renovaçâo da ETAR da Salgueira". Nota Técnica interna, B.T.W.P.

Favas, Paulo (1999) - Impacte Ambiental de Minas Abandonadas. O exemplo das Minas de Vale de Gatas (Sabrosa - Vila Real). Dissert. de Mestrado em Geociências área de especialização em Ambiente e Ordenamento do Território, apresentada ao D.C.T da FCTUC.

Fernandez - Rubio, R.; Fernandez Lorca, S.; Esteban Arlegui, J. (1986) - “Abandono de Minas: Impacto Hidrológico". Madrid: Ministério de Industria y Energia, IGME.

Gonçalves, A. C. Ramos (2007) - Mina da Panasqueira - Contributo para um Plano de Recuperação Ambiental e Paisagistica. Dissertação de mestrado em Geografia, Especialização em Geografia Física e Estudos Ambientais, apresentada à Faculdade de Letras da Universidade de Coimbra, 163 p. 
González, V. (1990) - “A Indústria Extractiva e o Ambiente”. Bol. de Minas, Lisboa, 27 (3) p. 311 - 323.

Guidicini, G; NIEBLE, C. (1983) - Estabilidade de taludes naturais e de escavação. Editora Edgar Blucher, S. Paulo, Brasil, 194 p.

I.T.G.E. (1989) - Manual de restauracion de terrenos y evaluacion de impactos ambientales em mineria, Série: Ingeneria GeoAmbiental, Madrid.

Machado, Maria José do Canto (1994) - "Impacto Ambiental Das Minas da Panasqueira na Bacia Hidrográfica do Rio Zêzere”. Contribuição para um estudo. Relatório Interno do I.G.M, Lisboa.

Ojea, Francisco Guitián (Coordenador) (1995) - Recuperación de las escombreras de la mina de lignitos de Meirama (A CORUNAA). Universidade de Santiago de Compostela.

Rebelo, Fernando (1994) - "Do ordenamento do território à gestão dos riscos naturais. A importância da Geografia Física salientada através de casos de estudo seleccionados em Portugal". Territorium, I, p. 7-15.

Valente, Sandra (2008) - "Feridas abertas na terra 1: da degradação dos sítios mineiros à sua recriação patrimonial o caso das Minas da Panasqueira". Comunicação apresentada ao Colóquio Ibérico de Estudos Rurais, Cultura, Inovação e Território, Coimbra, 18 p. 